\title{
A rare case of cephalothoracopagus janiceps conjoined twins
}

\author{
Seda Yilmaz-Semerci ${ }^{1}$, Tevfik Güzelbey ${ }^{2}$, Dilek Kurnaz ${ }^{1}$, Şahin Kalkan ${ }^{1}$, Merih Çetinkaya ${ }^{1}$ \\ ${ }^{1}$ Divisions of Neonatology and ${ }^{2}$ Radiology, İstanbul Kanuni Sultan Suleyman Training and Research Hospital, İstanbul, \\ Turkey.E-mail: sedayilmazsemerci@gmail.com \\ Received: 2nd October 2017, Revised: 22nd November 2017, 27th November 2017, Accepted: 2nd December \\ 2017
}

\begin{abstract}
SUMMARY: Yılmaz-Semerci S, Güzelbey T, Kurnaz D, Kalkan Ş, Çetinkaya M. A rare case of cephalothoracopagus janiceps conjoined twins. Turk J Pediatr 2018; 60: 751-754.

Conjoined twins represent a rare phenomenon of a monochorionic monoamniotic twin. Five types of conjoined twins have been described and thoracocephalopagus was reported to be seen with an incidence of 1 in 3 million. The etiology has not been elucidated yet. Therefore, more data is required to understand this entity better. Herein, we report a case of thoracocephalopagus.
\end{abstract}

Key words: thoracocephalopagus, conjoined twins, janiceps, neonate.

Conjoined twinning is a rare complication of monozygotic twins. It has been suggested to result from incomplete embryonic division between 13 and 15 days after conception. These are monochorionic and monoamniotic as they develop after differentiation of both chorion and amnion. ${ }^{1}$ The incidence of conjoined twins (CTs) has been reported as rare as $50,000-200,000 / 1 .^{2,3}$ It constitutes $1 / 546$ twin birth and $1 \%$ of monochorionic monoamniotic twins. ${ }^{4}$ It is more common in female fetuses. Thoracocephalopagus (TCP) was reported to occur with an incidence of 1 in 3 million as the rarest subtype of CTs. ${ }^{5,6}$ TCP is defined as twins that conjoined at the head and thorax having two faces each sides of the body. Therefore, TCP is also known as 'Janiceps' with the name of L. Janus, a Roman diety having two faces, caput and head.

To our best of knowledge there are only 17 cases of TCP reported in the literature. Herein, we present a seldom case of preterm TCP.

\section{Case Report}

From the second pregnancy of 21 year old Syrian mother, male twins were born via C-section in $28^{\text {th }}$ gestational week (GW). There was no family history for consanguinity or twinning. The participation of this case involved parental informed consents. Birth weight was $1800 \mathrm{~g}$ and babies were conjoined at the head, thorax and abdomen. Although appropriate resuscitation was applied, babies died shortly after birth. It was seen that patients had unique larynx during intubation. Postmortem physical examination elucidated two different faces on the opposite sides, having two distinct eyes, one nose, two ears and a normal mouth at one side, on the other side uncoupled orbits, two ears, an inchoative mouth and a skin tag on the forehead thought as proboscis (Figs 1 and 2) was observed. Twins had eight normal extremities and one umbilical cord with two arteries and a vein. Endoscopic examination demonstrated an entrance of larynx and a rudimentary larynx with a dead end. Genitourinary system was normal externally and bilateral testicles were palpable at the scrotum. Parents did not approve an autopsy so magnetic resonance imaging (MRI) performed. Postmortem whole body MRI represented that babies had two brains, two medulla spinalis, two lungs, one esophagus, one liver, two spleens and one pair of kidneys (Fig. 3). Chromosomal analysis resulted in 46, XY.

\section{Discussion}

CTs can be defined as a rare embryological accident with an unknown etiology. Although the reported incidence varies between $1 / 50,000$ and $1 / 100000$ live births, most of these pregnancies result with miscarriages and 


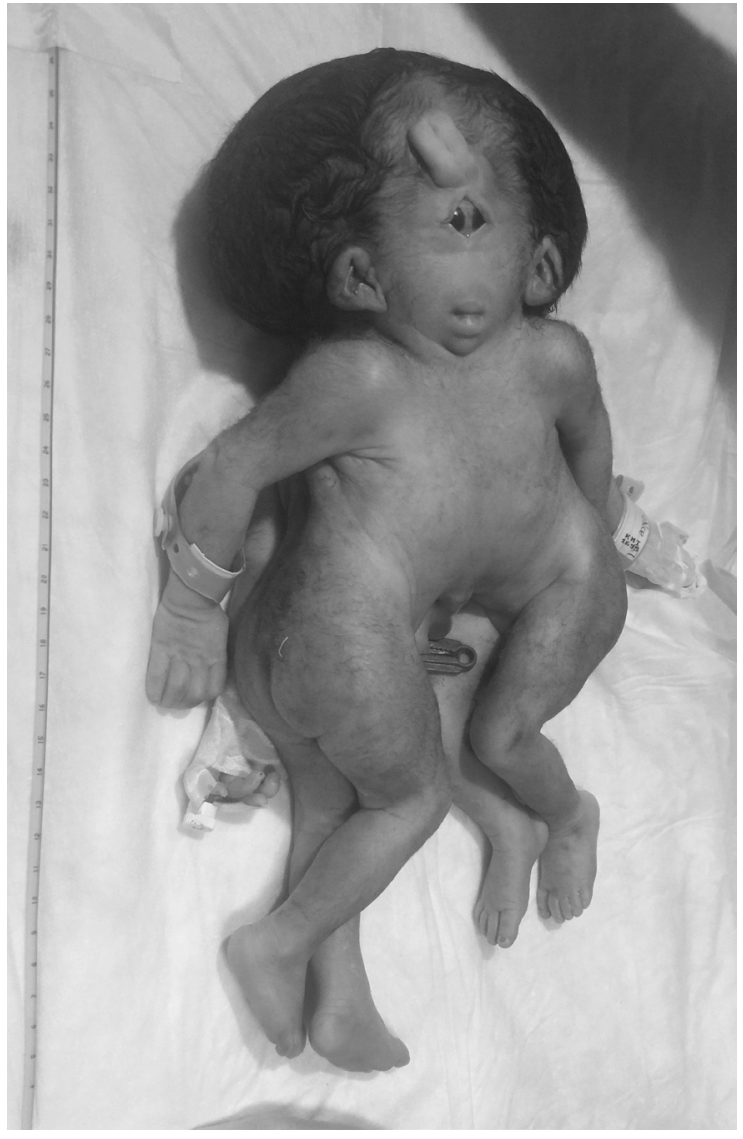

Fig. 1. Figure shows an uncoupled orbits, two ears, an inchoative mouth and a skin tag on the forehead thought as proboscis on one side.

stillbirth. Therefore, the real incidence was suggested to be higher. ${ }^{7}$

Five types of CTs as thoracophagus, omphalopagus, pygopagus, ischiopagus and craniopagus were described. CTs were divided into 3 major groups: twins with a ventral union, twins with a dorsal union and twins with a lateral union. The ventral union group was defined as cephalopagus (head), thoracopagus (chest), omphalopagus (umbilicus) and ischiopagus (hip) according to the fusion site. The dorsal union group was defined as pygopagus (sacrum), rachipagus (spine) and craniopagus (cranium). Lateral union group was defined as parapagus (side). ${ }^{8}$ The most common types were TCP was reported to be thoracoomphalopagus (56\%), thoracopagus (18.5\%), omphalopagus (10\%), followed by the others. ${ }^{5}$ The rarest of CTs have an estimated prevalance of $1 / 3$ million. ${ }^{3}$

TCP were also divided into two subtypes;

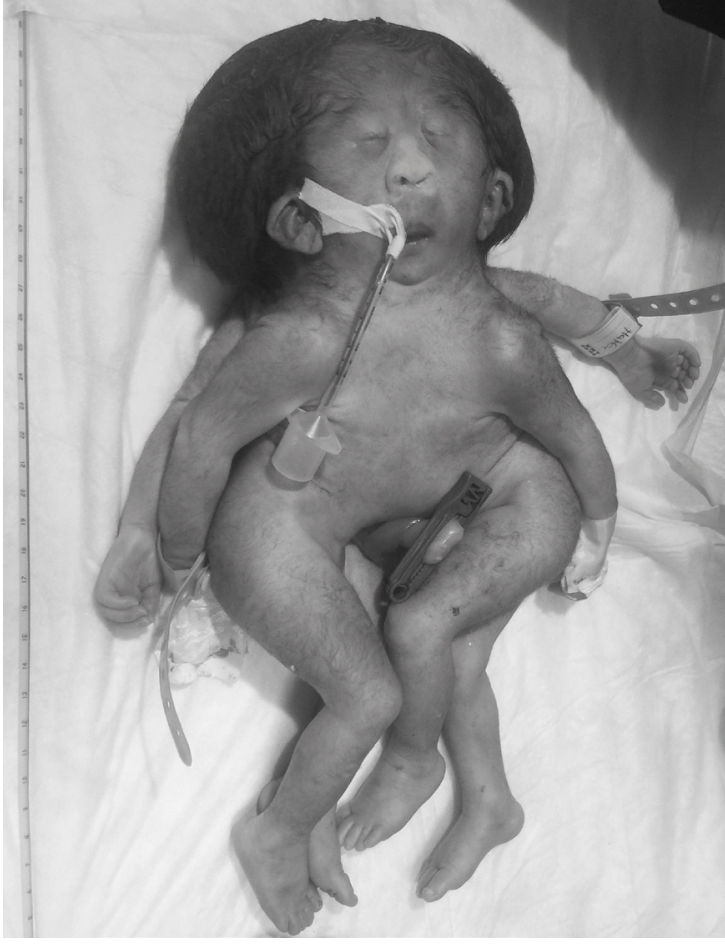

Fig. 2. Figure demonstrates two distinct eyes, one nose, two ears and a normal mouth at the other side.

Janiceps (diprosoporus) having two different faces at the opposite sides and non-Janiceps with a unique face at one side. Our case can be defined as Janiceps in accordance with the definition.

The etiology of CTs have not been fully understood. However, some risk factors including positive genetic history of twin and abnormality delivery, drugs for ovulation

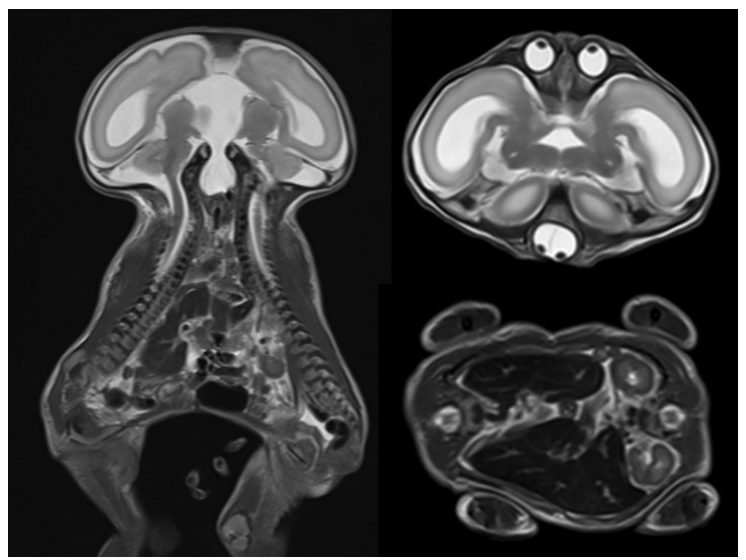

Fig. 3. Postmortem whole body MRI represented that babies had two brains, two medulla spinalis, two lungs, one esophagus, one liver, two spleens and one pair of kidneys. 
induction, treatment of infertility, exposure to harmful radiation were suggested to have a possible effect on the development of this rare condition. ${ }^{9}$ Although the family and pregnancy history did not cover these risk factors, our case was born to a Syrian mother that immigrated to Turkey during the civil war in their country. Therefore, we suggest that this might be associated with a possible use of chemical weapon. However, we could not elucidate it with the present history and findings. In addition, CTs were reported in a higher incidence ranging from 1:14,000 to $1: 25,000$ in Southeast Asia and Africa. While considering the incremental data of overall abnormalities in the neonates from this ethnicity, it may be possible to evaluate this as a 'war effect' on siblings.

CTs were reported to occur in female fetuses 3 times more than males ${ }^{4}$ but most of the stillbirths were reported to be males. In accordance, our cases were male and died shortly after birth. As mentioned above, CTs are monochorionic monoamniotic in all and caused by a lack in the division of the embryo plate at the 13-17th days of fertilization. ${ }^{10}$ TCP is a seldom entity but early diagnosis is possible during perinatal follow-up. First trimester diagnosis of TCP may be provided by high-resolution transvaginal transducer ultrasound. ${ }^{11}$ The mother was not followed for routine obstetric controls prenatally and applied to the emergency service with abundant vaginal hemorrhage so the diagnosis was made at birth. Prenatal diagnosis of TCP is important for detecting possible additional abnormalities and the decision of termination or establishing the delivery route. The prognosis and survival depend on the localization and degree of the fusion. As TCP twins cannot be separated surgically, CTs are usually not consistent with survival. While transvaginal route is the choice of medical termination before $18-20^{\text {th }} \mathrm{GW}$, delayed diagnosis requires surgical procedures for termination, which comes with the possible complications. As the mother had not had antenatal follow-up, this is the first TCP case born alive in the literature.

Majority of CTs are stillborn (40-60\%) and only $35 \%$ of them survive for the first 24 hours. ${ }^{11,12}$ Overall survival is reported to be $25 \% .{ }^{12}$ However, severe cases such as TCP are incompatible with survival since the surgical separation is unfeasible ${ }^{13}$. This case had a serious union with conjoined brains, complex vasculature and nested airways that make surgical separation impossible. At the same time there was no way to survive without separation for the case because having severe immaturity with inchoative organs in one of the twins. Postnatal imaging modalities including ultrasonography and MRI should be used to detect the fatal defects in different organ systems. ${ }^{14}$ Although our patient died shortly after birth, MRI showed two brains, two medulla spinalis, two lungs, one esophagus, one liver, two spleens and one pair of kidneys for our case. Therefore, we suggest that this is the first case of TCP who had only one kidney for two babies in spite of the number of other organs were normal. However, we cannot explain this difference with the present history. We may suggest that different subtypes of TCP may be defined with future case reports.

Herein, we reported a case of Janiceps TCP that represents the rarest form of CTs. Asian ethnicity and possible effects of civil war may be suggested as the risk factors for our case. Early prenatal detection of CTs without survival in prospect is important for timely pregnancy termination transvaginally, which provides less surgical intervention and prevents possible complications. This case also shows the impossibility of survival in these cases. Therefore, prompt diagnosis and termination should be considered in the early phases of pregnancy.

\section{REFERENCES}

1. Graham III GM, Gaddipati S. Diagnosis and management of obstetrical complications unique to multiple gestations. Semin Perinatol 2005; 29: 282-295.

2. Mian A, Gabra NI, Sharma T, et al. Conjoined twins: From conception to separation, a review. Clin Anat 2017; 30: 385-396.

3. Spitz L. Conjoined twins. Prenat Diagn 2005; 25: 814-819.

4. Oleszczuk JJ, Oleszczuk AK. Conjoined Twins. In: Blickstein I, Keith LG (eds). Multiple Pregnancy: Epidemiology, Gestation, and Perinatal Outcome. London: CRC Press 2005: 365-387.

5. Abossolo T, Dancoisne P, Tuaillon J, Orvain E, Sommer JC, Rivie `re JP. Early prenatal diagnosis of asymmetric cephalothoracopagus twins. J Gynecol Obstet Biol Reprod (Paris) 1994; 23: 79-84. 
6. Sharma D, Jhobta A, Azad JR, Dhiman DS, Pandith M, Sharma S. Cephalothoracopagus janiceps asymmetros twins: Antenatal sonographic diagnosis. J Clin Ultrasound 2013; 41: 199-202.

7. Mutchinick OM, Luna-Muñoz L, Amar E, et al. Conjoined twins: A worldwide collaborative epidemiological study of the International Clearinghouse for Birth Defects Surveillance and Research. Am J Med Genet C Semin Med Genet 2011; 157C: 274-287.

8. Aneja A, Rajanna DK, Reddy VN, Mayilvavaganan KR, Pujar P. Conjoined twins: A rare case of thoracoomphalagus. J Clin Diagn Res 2013; 7: 1471-1472.

9. Kamalian N, Shirani S, Soleymanzadeh M. Thoracoomphalo-ischiopagus tripus conjoined twins: Report of a case. J Forensic Res 2011; 2: 117. doi: 10.4172/21577145.1000117
10. Kapoor M, Sachdev N, Agrawal M. Conjoined twins. J Obstet Gynaecol India 2013; 63: 70-71.

11. Pierro A, Kiely EM, Spitz L. Classification and clinical evaluation. Semin Pediatr Surg 2015; 24: 207-211.

12. Entezami M, Albig M, Knoll U, et al. Ultrasound diagnosis of fetal anomalies. Stuttgart: Thieme, 2003: 306-308.

13. Rios LT, Araujo Júnior E, Nardozza LM, Nacaratto DC, Moron AF, Martins MdaG. Prenatal diagnosis and postnatal findings of cephalothoracopagus janiceps disymmetros: A case report. Case Rep Med 2012; 2012: 273526 .

14. Wataganara T, Ruangvutilert $P$, Sunsaneevithayakul $P$ Russameecharoen K, Nawapun K, Phithakwatchara N. Three-dimensional ultrasound for prenatal assessment of conjoined twins: Additional advantages? J Perinat Med 2017; 45: 667-691. 